Vietnam Academy of Science and Technology
Vietnam Journal of Earth Sciences
http://www.vjs.ac.vn/index.php/jse

\title{
Algorithm and program for earthquake prediction based on the geological, geophysical, geomorphological and seismic data
}

\author{
Ngo Thi Lu' ${ }^{1 *}$, Rodkin M.V. ${ }^{2}$, Tran Viet Phuong ${ }^{1}$, Phung Thi Thu Hang ${ }^{1}$, Nguyen Quang3, \\ Vu Thi Hoan ${ }^{1}$ \\ ${ }^{1}$ Institute of Geophysics, Vietnam Academy of Science and Technology \\ ${ }^{2}$ International Institute of Earthquake Prediction Theory and Mathematical Geophysics (IEPT), Russian Academy of \\ Sciences \\ ${ }^{3}$ General Department of Geology and Minerals, Ministry of Natural Resources and Environment, Vietnam \\ Received 4 November 2015. Accepted 15 August 2016
}

\section{ABSTRACT}

By applying an improved method of the Earth's crust classification, we develop an algorithm and build an earthquake prediction program using a combination of geological, geophysical, geomorphological and seismic data.

This program includes a system of multiple windows with different functions, which can divide fault zones into the different segments by the maximum magnitude values Mmax. Using the constructed program, we carried out an earthquake prediction test for the Northwest Vietnam by a combination of geological, geophysical, geomorphological and seismic data. According to the received results, zoning maps of maximum earthquake prediction for the researched region has been established. The results show that the areas, capable of generating earthquakes with Mmax = 6.5 - 6.8 are primarily concentrated along some major fault zones such as Lai Chau-Dien Bien, Son La, Song Ma, Song Da, Tuan Giao or near the intersection of these fault zones. The received results show a good accordance with the actual seismotectonic characteristics of the researched region.

Keywords: earthquake, earthquake prediction, maximum magnitude.

(C2016 Vietnam Academy of Science and Technology

\section{Introduction}

In recent years, earthquake and tsunami hazards have been increasing worldwide, especially in the Southeast Asia. The tsunamigenic earthquake in Sumatra (Indonesia) on 26 December 2004 (M9), The earthquakes in Sichuan (China) on 12 May

*Corresponding author, Email: ngothilu@yahoo.com
2008 (M7.9), in Qinghai (China) on 14 April 2010 (M6.9), in Myanmar on 24 March 2011 (M6.9); and particularly the latest disaster caused by earthquake and tsunami in Honshu, Japan on March 11, 2011 (M8.8) have brought serious losses to people, property as well as the environment. The actual situation makes the earthquake and tsunami prediction, which is always being a global-scale difficult problem, become more and more urgent and 
attract a lot of scientists' attention. To solve such critical problem in any territory, one of the most important tasks is to develop and establish a program that allows forecasting the occurrence time, location and magnitude of the earthquake in the near future.

The research on earthquake prediction in Vietnam is primarily carried out using two main groups of methods that are maximum earthquake prediction $\left(\mathrm{M}_{\max }\right)$ based on geological, geophysical data and $\mathbf{M}_{\max }$ prediction based on statistical analysis of seismic data.

Maximum earthquake prediction based on the geological, geophysical data consists of main methods such as Mmax calculation method according to the dimension of seismogenic zone that has been applied in several works (Cao Dinh Trieu, 1999; Nguyen Dinh Xuyen (Editor) et al., 1996; Nguyen Dinh Xuyen, 2002; Pham Van Thuc, 1985, 2007; Phan Trong Trinh et al., 2012, 2013. Bui Van Duan, et al., 2013.

The accuracy of this method depends on the accuracy of determining the size of seismogenic fault and the thickness of seismic layer. This method is appropriate for regions with active faults, but it cannot predict Mmax in regions without active faults. Some methods such as tectonophysics; experts' opinion evaluation; combination of geological - geophysical data have been initially applied in several works in Vietnam based on using the structural characteristics of Earth's crust (Cao Dinh Trieu et al., 2006 ; Cao Dinh Trieu et al., 2007; Gubin I. E., 1950). The methods of maximum earthquake prediction based on statistical analysis have been used in a variety of research projects in the world as well as in Vietnam (Dang Thanh Hai, 2003; Gumbel E. J., 1958; Gutenberg B. et al., 1954; Ngo Thi $\mathrm{Lu}$ (Project manager), 2011, 2012, 2013; Nguyen Hong Phuong, 1991, 1997, 2001, 2014; Tran Thi My Thanh, 2002; Vu Thi Hoan, Ngo Thi Lu et al, 2014. Some methods such as maximum likelihood method, utilization of earthquake manifestation rules, seismic extrapolation, Mmax prediction method based on foreshock - aftershock activities (Nguyen Dinh Xuyen et al., 2003) and magnitude - time model to assess the probability of earthquake occurrence have also been applied in Vietnam and obtained some results. For example, the algorithm of earthquake prediction based on magnitude time model has been applied to Lai Chau Dien Bien area as well as the northern part of Vietnam and received some encouraging results (Dang Thanh Hai et al., 2002; Dang Thanh Hai, 2003). Thus, earthquake prediction in Vietnam is mainly medium and long term forecast on the basis of the earthquake-generating mechanism through statistical algorithm. The maximum likelihood method and the method using Gumbel distribution function are of the statistical probabilistic characteristics. They can be conveniently and easily applied. However, they cannot determine the occurrence time, coordinates of the earthquake and the reliability of results strongly depends on the completeness and accuracy of data used. The seismic extrapolation method is based on the assumption that the maximum earthquake occurring on a segment of the fault can also occur in other segments of that fault, or on other faults with the similar role and regional tectonic feature. This principle can lead to the misjudgment of Mmax because the strongest observed earthquake may not be the maximum earthquake that is likely to happen; furthermore, the seismotectonic conditions can hardly be considered homogenous.

In (Ngo Thi Lu et al., 2013), the authors have combined two methods, which are the tectonophysics (Reisner G. I. et al., 1993, 1996) and the statistical model (Grishin A. P., 2001; Grishin A. P. et al., 2001), to build a program of short-term earthquake prediction with the use of 5 typical parameters of the Earth's crust (the heat flow density, the Earth's crust thickness, the terrain elevation, the isostatic anomalies of the Earth's crust 
and the depth to crystalline basement). This approach is not only more efficient, allowing the elimination of limitations mentioned above, but also produces a new innovative result with the scientific and practical significance. However, through the testing process with this earthquake prediction program for Vietnam and the Southeast Asia, it shows some limitations that should be fixed. Therefore, in this paper we will propose a new approach that allows overcoming some limitations of the program as explained below.The limitation due to the lack of the heat flow density data can be avoided by using additional data on tectonic-geomorphic indices and lineament length density in earthquake prediction. This new idea is highly feasible because the tectonic-geomorphic indices and lineament length density are the parameters characterizing the rate of tectonic movement of the Earth's crust, so their values also represent properties and characteristics of a type of the Earth's crust at a certain subregion. Accordingly, when these parameters are identified in a place where the earthquake with magnitude $M$ has occurred, it is possible to predict the possibility of the earthquake with magnitude $\mathrm{M}$ in another sub-region with similar characteristics of the Earth's crust. According to this principle, the use of additional data on tectonic-geomorphic indices and lineament length density combined with other parameters of the Earth's crust in earthquake prediction will definitely increase the convince as well as the accuracy of forecast results.

The program developed in (Ngo Thi Lu et al., 2013) does not have the functions of conversion to a unique coordinate system of the grids and assigning weights to the characteristic parameters of the Earth's crust, and this surely affects the uniformity and limits the reliability of calculation results. This limitation will be overcome by building a new software with the addition of functions to uniform the coordinate systems of the grids and assigning the weights for the parameters used in the calculation. Due to the characteristics of each type of data, it is necessary to have different interpolation methods for different types of data. Especially in cases of lack of measurement data, a new method can be used to calculate the interpolated values at the points with no data (called scattered interpolation). Then, the interpolation values will be inserted into the corresponding positions of the grids and the software with the function of scattered interpolation will be added to the new program. This is an innovation to overcome one of the drawbacks of the program developed in (Ngo Thi Lu et al., 2013).

\section{Research methodology and algorithm}

\subsection{Research methodology}

In this paper, we have applied the method proposed in the works (Reisner G. I. et al., 1993, 1996). The method is based on the following principles: Observation of elevation allows us to learn about the contrast and intensity of tectonic activity in the present. The structure of crystalline basement, the thickness of the Earth's crust are the evidence of the heterogeneity in neotectonic movement. Additionally, the isostatic equilibrium and geothermal features are also the distinct evidence of the movement characteristics of the Earth's crust. Therefore, in order to divide the blocks of the Earth's crust according to its seismogenic characteristics, the authors of works (Reisner G. I. et al., 1993, 1996) used 5 basic characterizing parameters as follows:

Density of the heat flow (Q), in unit of $\mathrm{mW} / \mathrm{m}^{2}$,

The thickness of the Earth's crust (T) (in $\mathrm{km})$,

Topographic elevation (R) (or the bathymetry) (in km),

Isostatic anomalies of the Earth's crust (I) (changable unit, depending on the value of parameter I for each study area);

The depth to crystalline basement or sediment thickness (F) (in km). 
The normal size of window to display the coordinate grid is $20^{\prime} \times 30^{\prime}$, corresponding to the size of a 1:100,000 topographic map sheet.

Based on practical experience of applying this method in a variety of places in Europe, the authors of (Reisner G. I. et al., 1993, 1996) recommend a number of regulations as follows:

The values of input data is transferred to a standard benchmark of 32,000 units.

Using 20 levels to divide the value, so $1 / 20$ of the dividing range will be equivalent to 1,600 units.

Regulating the value of input data according to the dividing range and the standard value of data. For example, the lowest value of data is Min, the highest value is Max, so the physical value is (Max Min) $/ 20=32,000 / 20=1,600$ regulatory units.

In this paper, we have also applied the experience of the authors from works (Reisner G. I. et al., 1993, 1996) in transferring all original data to a standard benchmark. If the conventional values are divided according to 20 levels from 1 to 20 , it is possible to determine the dividing range (or called dividing window) for each characterizing parameter: (Max - Min)/20. However, due to the advantage of the selected language and the processing ability of the program, during data processing, the value of dividing threshold (window) is not necessarily be chosen as (Max - Min)/20 but can also be changeable to match the real value of the input data. Thus, in the new algorithm, we have modified the division of threshold according to the percentage scale (\%) and will build a system of open windows that allows the optional selection of the thresholds appropriate for the real value band of each characterizing parameter mentioned above.

After dividing the blocks of the Earth's crust under the characteristics of structure into a grid of cells, by comparing and integrating the grid cells that capture the maximum earthquake with the grid cells with no earthquake, but having similar structural characteristics of the Earth's crust, one can conclude that the latter can have the same ability to accumulate and release energy as the former. The analysis has been conducted as follows:

- The Earth's crust zoning map is superimposed on the map of observed maximum earthquake activity $\left(\mathrm{M}_{\max }\right)$.

- The value of $\mathbf{M}_{\max }$ detected in any grid will be assigned to other grids with the same characteristic of the Earth's crust (the same type) without concerning the weaker earthquakes or no earthquakes have occurred within the latter.

Thus, through the analysis, we clearly recognize the outstanding advantage of the earthquake prediction method according to the structural characteristics of the Earth's crust that allows forecasting the maximum earthquake for the region without seismic data.

\subsection{Algorithm}

Based on the above analysis, in order to overcome the limitations of the program developed in (Ngo Thi Lu et al., 2013), we have built a new algorithm with the aim of developing and adding some interface windows to the program to perform the following functions:

- The program includes a system of windows enabling the selection and addition of many different parameters that characterize the seismogenic potential of the Earth's crust such as geological, geophysical, geomorphological, seismic parameters, and elevation gradient, etc.

- The program can define and change the weight of each parameter according to its importance in each separate region.

- The program has the function of scattered interpolation for some types of data (which can be interpolated) in cases of lack of data. For example, in case of lack of data on 
geomorphological index and lineament density, the scattered interpolation can be carried out by using the data of adjacent points.

With such requirements, a new algorithm of earthquake prediction program based on a combination of geological, geophysical, geomorphological and seismic data consists of the following steps:

Step 1: Dividing the study area into a grid of cells having dimensions of $\mathrm{dx}$, dy according to the research scope and the target of tasks to be solved.

Step 2: Grouping for the cells in the grid of study area according to the characteristics of the Earth's crust:

- Input data of $\mathrm{k}$ different parameters will be the set of arrays X[i], Y[i], level GT[i] corresponding to each parameter, in which level GT is the value level representing the weights of parameters..

- Interpolating to define the arrays xi, yi, zi for every parameter:

$+\mathrm{i}=1 \rightarrow \mathrm{k}$ (k is the number of characterizing parameters of the Earth's crust used in the calculation)

- Interpolating X, Y, level GT according to the selected region and step $\mathrm{dx}, \mathrm{dy} \rightarrow \mathrm{xi}$, yi, zi

where $\mathrm{zi}$ is a set of different arrays for different parameters, and $\mathrm{xi}$, yi are the coordinates of the point with parameter value of zi.

- Defining a new array "level GT" with integer data type, reflecting the values of the array zi according to the discrete division (similar to the classification of levels: low, medium, fair, high, extremely high, etc.)

$+\mathrm{i}=1 \rightarrow \mathrm{k}$

- $\mathrm{j}=1 \rightarrow \mathrm{n}$ ( $\mathrm{n}$ is the number of elements of the array $x j, y j, z j)$

- Determining the values of parameter [i]. (level GT[j]) from the value of [i].z[j] based on the given threshold ([i].z[j] is the value of $i$-th parameter, in $j$-th position in the grid);

- Identifying the group of each cell at the $\mathrm{xi}$, yi coordinate

$+\mathrm{i}=1 \rightarrow \mathrm{n}$

- If group[i] = null (no value assigned)
- Group[i] $=\max ($ group $)+1$ (assigning the new value that has not been used for group[i])

- $\mathrm{j}=\mathrm{i}+1 \rightarrow \mathrm{n}$

- $\mathrm{m}=1 \rightarrow \mathrm{k}$ (k is the number of parameters)

- If parameter [m].value[i] is different from parameter $[\mathrm{m}]$. value $[\mathrm{j}] \rightarrow \operatorname{diff}=\operatorname{diff}+1$ (diff is the variable indicating differences between the parameters)

- If diff is small enough $\rightarrow$ group[j] $=$ group[i]; cell:

Step 3: Determining $M_{\max }$ for each grid

- Determining the number of grid cells: $\mathrm{kx}$, ky based on the size of array xi, yi that has been obtained from the interpolation ( $\mathrm{kx}$ is the number of grid cells on the $\mathrm{x}$ axis (the number of columns), ky is the number of grid cells on the $\mathrm{y}$ axis (the number of rows), $\mathrm{kx} \neq \mathrm{ky}$ ).

- Defining arrays Xm, Ym and me which are respectively the coordinates and magnitudes of events in the earthquake catalog used; from which $\mathrm{m}[\mathrm{i}]$ is determined to be the maximum magnitude of the $i$-th cell among $\mathrm{n}$ grid cells;

- Defining 2 arrays: ixl and iyl are the order numbers of columns and rows, respectively, these two variables are used to display the results in the grid cells:

$+\mathrm{i}=1 \rightarrow \mathrm{n}$

- Determination of ixl[i] knowing value $x[i]$ in the $i$-th column (according to the extent of study area and the size of $\mathrm{dx}$ )

- Determination of iyl[i] knowing value $y[i]$ in the i-th row (according to the extent of study area and the size of dy);

- Creating the array $M_{\max }$ with the number of elements equal to the number of identified groups. Determining $\mathbf{M}_{\max }$ for each group as follows:

$+\mathrm{g}[\mathrm{i}]$ is the name of group in the $\mathrm{i}$-th grid cell, expressed in terms of the ordinal number

$+\mathrm{i}=1 \rightarrow \mathrm{n}$

- If $\mathrm{m}[\mathrm{i}]>\mathrm{M}_{\max }[\mathrm{g}[\mathrm{i}]]$, so $\mathrm{M}_{\max }[\mathrm{g}[\mathrm{i}]]=\mathrm{m}[\mathrm{i}]$

With the basic steps described above, the ideas of program can be summarily represented by the diagram in Figure 1. 


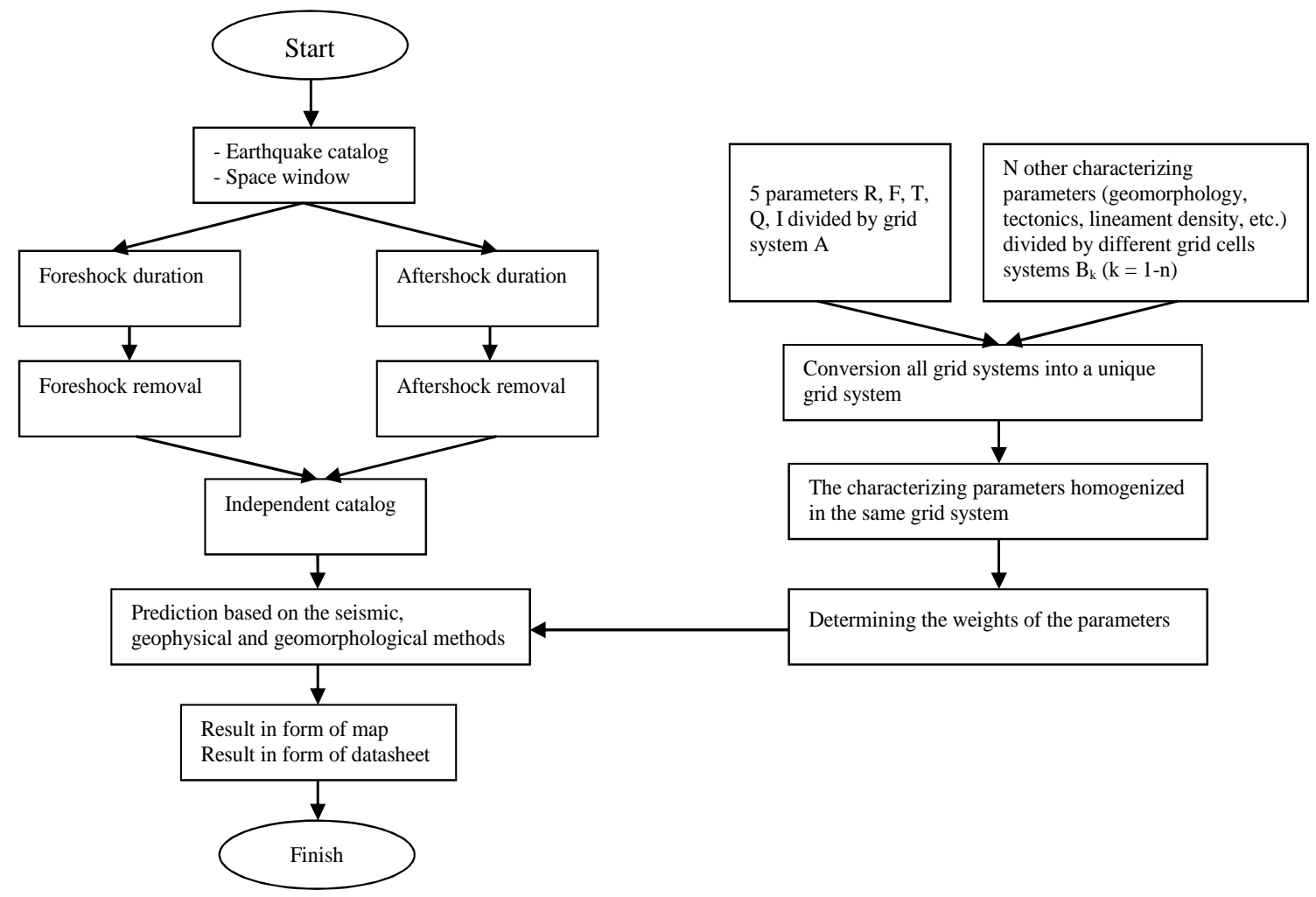

Figure 1. Diagram of ideas for earthquake prediction program based on the geological, geophysical, geomorphological and seismic data

\subsection{Earthquake prediction program}

Data entry interface of earthquake prediction program based on a combination of geological, geophysical, geomorphological and seismic data is presented in Figure 2. The windows on the interface have the following functions (Figure 2):

- The window in the place numbered 1 is a data entry window (updating or deleting data by the buttons "add" and "delete"). The system of open windows in the program allows adding an unlimited number of other parameters that characterize the seismogenic potential of the Earth's crust (if any).

- The window numbered 2 displays the data field including 3 columns: $\mathrm{Y}, \mathrm{X}$ and the values of parameters.

- The place numbered 5 enables the determination of weights for the parameters by using cross mark in the graph of the fifth place to divide the boundaries between the values of parameters. The values of breakpoints will be displayed in the window numbered 4 . When adjusting the weight for each parameter, it is possible to modify the types of data to display according to normal interpolation or logarithmic interpolation near the place numbered 3 .

- The place numbered 6 is used to set the limit (coordinate frame) of the study area (xmax, xmin, ymax, ymin) by changing the numerical values in the 4 textboxes.

- The textboxes in the place numbered 7 allow the optional selection of the cell size in the grid covering the study area $(\mathrm{dX}, \mathrm{dY})$.

- The "Proc" button is used for data processing and earthquake prediction; the "create map" button is used to create the map and to view the results of earthquake prediction in the "export map" tab (Figure 3). 
Vietnam Journal of Earth Sciences 38(3), 231-241, DOI: 10.15625/0866-7187/38/3/8708

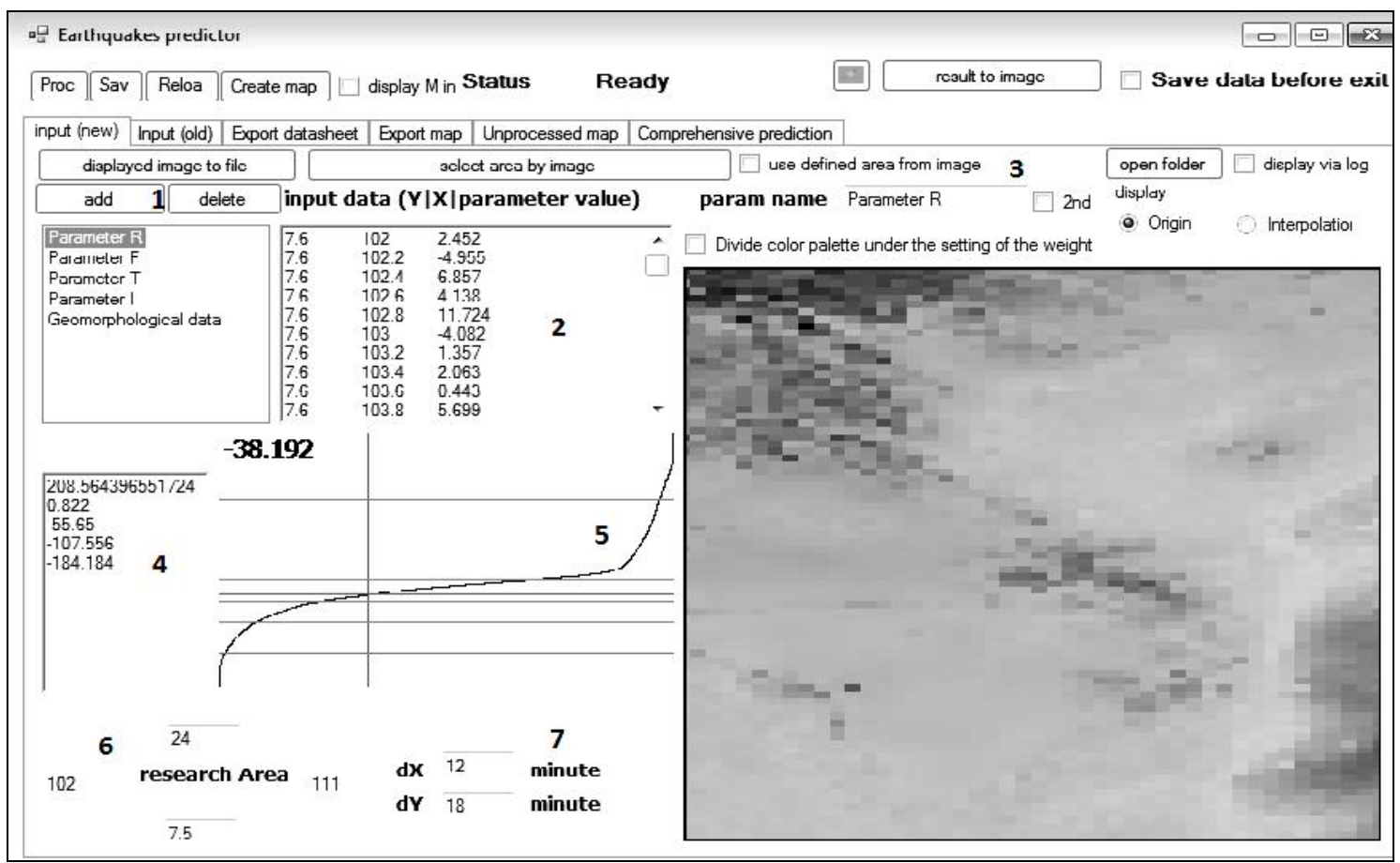

Figure 2. Interface of data import of earthquake prediction program based on geological, geophysical, geomorphological and seismic data

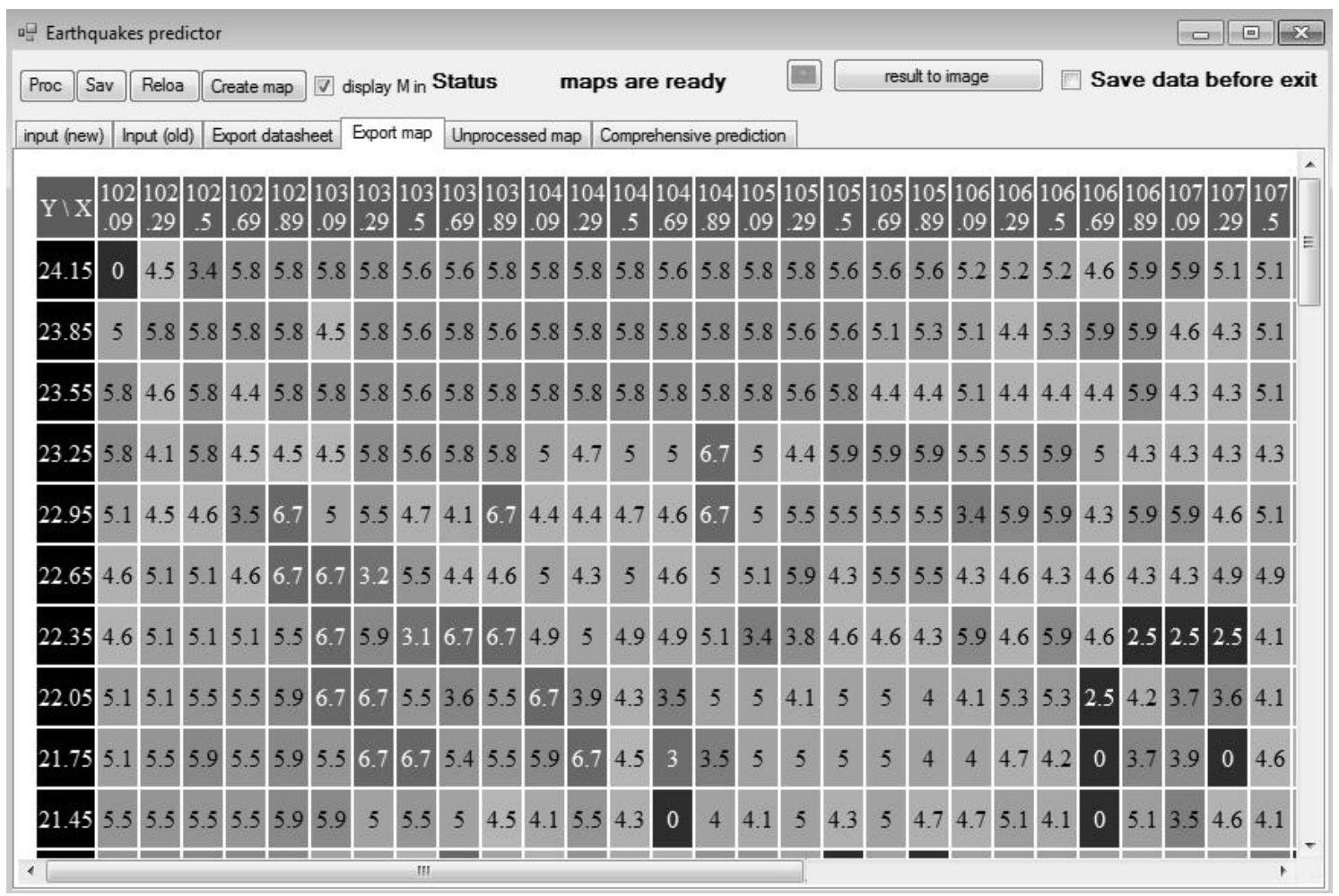

Figure 3. Program interface displaying results in the map format 
N.T. Lu, et al./Vietnam Journal of Earth Sciences 38 (2016)

\section{Apply the earthquake prediction program for the Northwestern Vietnam and discussion}

With this objective, the study area is selected as shown in Figure 4 within the coordinates: $\varphi=20.0-23.50 \mathrm{~N} ; \lambda=102.0$ Earth's crust, topographic elevation, isostatic anomalies of the Earth's crust and depth to crystalline basement are derived from (Ngo Thi $\mathrm{Lu}$ et al., 2011, 2013). The data on tectonic-geomorphic indices and lineament density are collected and calculated by the authors; and the data on the gradient of the geoid height is provided by the World Data Centre A, Russian Academy of Sciences. The earthquake catalogue used in the calculation includes 1,376 earthquakes in the study area and adjacent region from 1137 to 2014 with the magnitudes $\mathrm{M}=1.7-7.5$.

The established program has been applied to predict the maximum earthquake in the Northwestern Vietnam based on the geological, geophysical, geomorphological and seismic data through 2 variants with different input data:

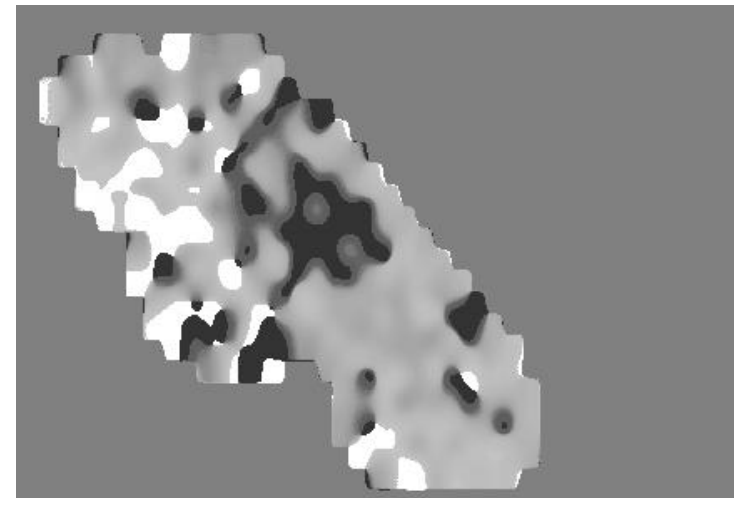

b)

Figure 4. Result of earthquake prediction program for the Northwestern Vietnam based on the geological, geophysical, geomorphological and seismic data in terms of a map (a) and image (b). ( $\varphi \mathrm{x} \lambda=0.15^{\mathrm{o}} \times 0.15^{\circ} ; \mathrm{T}$, $\mathrm{R}, \quad \mathrm{I}, \mathrm{F}, \mathrm{V}, \mathrm{L}, \mathrm{G}=5 \%$ )

- Variant 1: $\varphi \times \quad \lambda=0.17^{\circ} \times 0.17^{\circ} ; \mathrm{T}$,

$\mathrm{R}, \quad \mathrm{I}, \mathrm{F}, \mathrm{V}, \mathrm{L}, \mathrm{G}=7 \%$

- Variant 2: $\varphi \times \quad \lambda=0.15^{\circ} \times 0.15^{\circ} ; \mathrm{T}$,

$\mathrm{R}, \mathrm{I}, \mathrm{F}, \mathrm{V}, \mathrm{L}, \mathrm{G}=5 \%$

Where: $\varphi, \lambda$ are the sizes of a grid cell;

$\mathrm{R}, \mathrm{F}, \mathrm{T}, \mathrm{I}, \mathrm{V}, \mathrm{L}, \mathrm{G}$ are the dividing thresholds values of the corresponding characterizing parameters used in the calculation (the thickness of the Earth's crust, terrain elevation, isostatic anomalies, the depth of crystalline basement, tectonicgeomorphic indices, lineament length density and gradient of the geoid height).

It should be noted that in the calculation process, the value of each parameter is selected according to a separate weight and this selection also varies by each calculation variant so that the characteristic of that parameter is most clearly shown (e.g. the interface in Figure 2).

The results of prediction by 2 variants are slightly diferent; however, the locations of seismic hazard areas forecasted by both variants are basically identical. In the framework of this paper, we only present the results of the variant 2 (Figure 4). Based on these results, we have established the Possible maximum magnitude earthquake zoning map for the Northwestern Vietnam (Figure 5).

As can be seen in Figure 4(a) and Figure 5:

The maximum earthquake-generating areas with $\mathrm{M}_{\max }=6.5-6.8$ are concentrated along major fault zones such as Lai Chau-Dien 
Vietnam Journal of Earth Sciences 38(3), 231-241, DOI: 10.15625/0866-7187/38/3/8708

Bien, Son La, Song Ma, Song Da, Tuan Giao area or near the intersections of these fault zones. Especially, along the Song Ma fault, its northwestern segment is predicted to generate earthquake with magnitude $\mathrm{M}_{\max }=6.8$; however, its southern segment at the intersection with higher-ranked fault zones, from Muong Lat to Ngoc Lac, Thanh Hoa is predicted to generate earthquake with $\mathrm{M}_{\max }=5.7$.

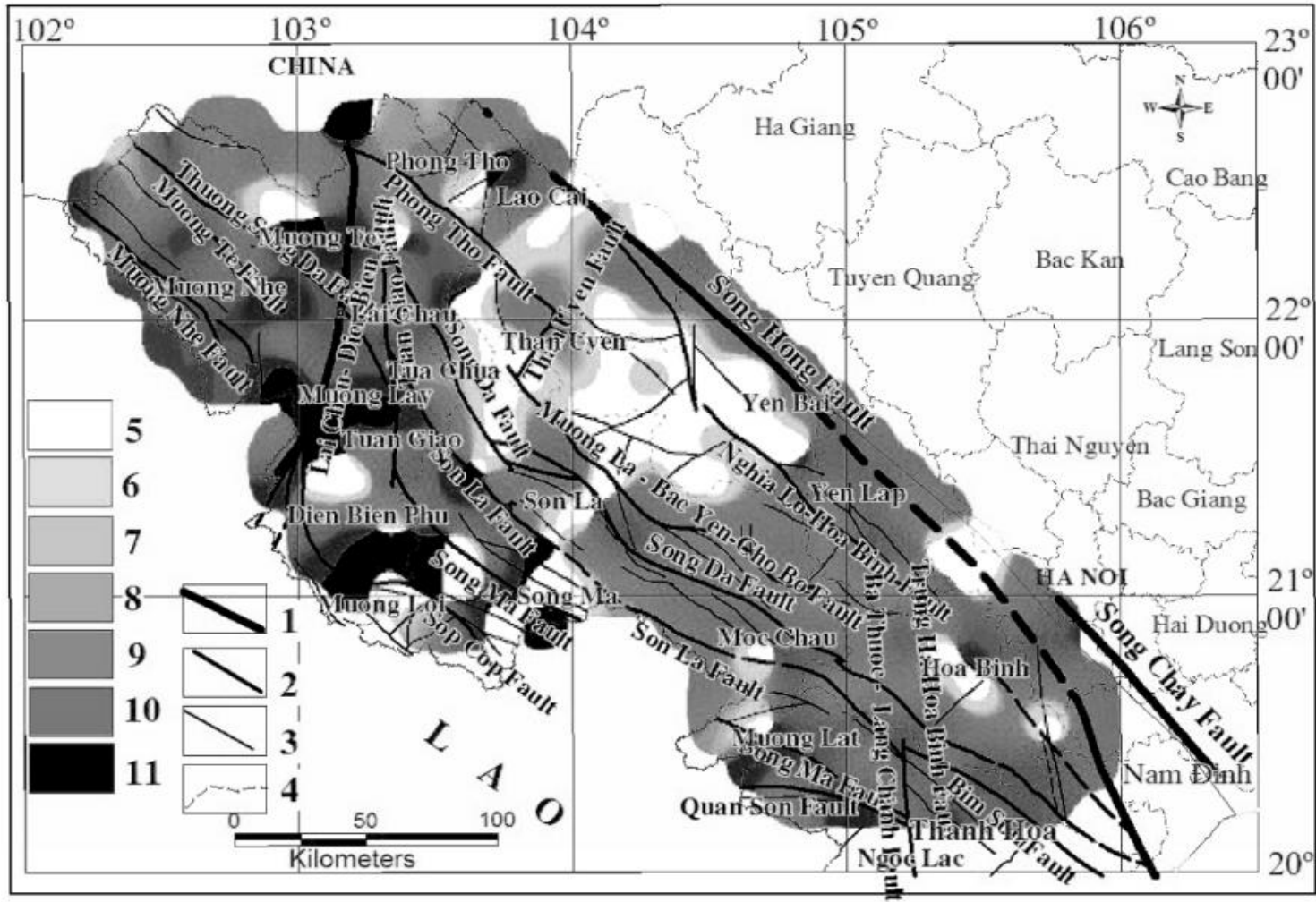

Figure 5. The Possible maximum magnitude earthquake zoning map for the Northwestern Vietnam based on the geological, geophysical, geomorphological and seismic data

Note: 1, 2 - The first-ranked and second-ranked faults respectively; 3 - The undivided high-ranked faults; 4 - National border; $5-\mathrm{M}<3.0 ; 6-\mathrm{M}=3.0-3.9 ; 7-\mathrm{M}=4.0-4.5 ; 8-\mathrm{M}=4.6-4.9 ; 9-\mathrm{M}=5.0-5.5 ; 10-\mathrm{M}=5.6-6.0 ; 11$. $\mathrm{M}>6.0$

According to the results of previous studies, many authors have predicted the maximum earthquake in Song $\mathrm{Ma}$ area (including the entire Song Ma fault zone and adjacent regions) with the different values of $\mathrm{M}_{\max }$ ranging from 7.1 to 8.5 (Cao Dinh Trieu, 1999; Cao Dinh Trieu et al., 2006, 2007; Nguyen Dinh Xuyen et al., 1996; Nguyen Dinh Xuyen, 2002; Tran Thi My Thanh, 2002). In fact, the maximum earthquakes occurred in this area just with magnitude $\mathrm{M} x$
$=5.7$. Along Nam Khum fault zone and at the intersection of Song Da and Dien Bien-Lai Chau fault zones, Tua Chua and Than Uyen areas are predicted to have the earthquake hazard with $\mathrm{M}_{\max }=5.7$.

Thus, the application of the established program to predict earthquake not only has the results that are perfectly suited to the actual characteristics of seismic activities but also allows dividing the faults into the segments with the different level of 
N.T. Lu, et al./Vietnam Journal of Earth Sciences 38 (2016)

seismogenic possibility (based on $\mathrm{M}_{\max }$ ). This is the issue that attracts a lot of seismologists' attention. However, these are only the initial experimental results, so it is difficult to avoid the debate on the reliability and applicability of the established program. In the future, it is necessary to test this program in the seismic zones with various actual conditions, e.g. active seismic areas in the Southeast Asia or Kavkaz area in Russian Federation, to form the sound basis for the reliability and applicability of established programs in seismology.

\section{Conclusions}

Based on the application of new approach, a new algorithm and a maximum earthquake prediction program according to geological, geophysical, geomorphological and seismic data have been established. The program includes a system of windows, enabling the selection and addition of different parameters characterizing the seismogenic possibility of the Earth's crust. The program allows not only defining and changing the weight of each parameter according to its importance in each separate region but also has the function of scattered interpolation for some types of data (which can be interpolated) in cases of lack of data.

The established program has been applied to predict the maximum earthquake in the Northwestern Vietnam based on the geological, geophysical, geomorphological and seismic data; and some results have been obtained through 2 variants with different input data. The locations of seismic hazard areas forecasted by 2 variants are basically identical.

Based on the obtained results, the Possible maximum magnitude earthquake zoning map for the Northwestern Vietnam has been established. These results not only prove perfectly suited to the actual seismic activities in the study area but also indicate that the program can divide the fault zones into the different segments according to the level of seismic hazard $\mathrm{M}_{\max }$.

\section{Acknowledgements}

The article has been finished with the support of the independent project of Vietnam Academy of Science and Technology (Code VAST.DL.01/14-16), the authors would like to sincerely thank for this support.

\section{References}

Bui Van Duan, Nguyen Cong Thang, Nguyen Van Vuong, Pham Dinh Nguyen, 2013. The magnitude of the largest possible earthquake in the Muong La - Bac Yen fault zone. Journal of Sciences of the Earth 35, 53-49.

Cao Dinh Trieu, 1999. Probable approach for long-term earthquake prediction in Vietnam based on the regulation of epicentral distribution. Journal of Geology, Series A (251), 14-21, Hanoi (in Vietnamese).

Cao Dinh Trieu, Nguyen Huu Tuyen, Thai Anh Tuan, 2006. The correlation between the structure of the Earth's crust and seismic activities in the Northwest region of Vietnam". Journal of Sciences of the Earth, 28, 155-164, Hanoi (in Vietnamese).

Cao Dinh Trieu, Ngo Thi Lu, Cao Xuan Bach et al., 2007. Prediction of maximum earthquake occurrence in Vietnam on the basis of crustal characteristics". Proceedings of the $5^{\text {th }}$ Vietnam's Scientific Conference on Geophysics, 159171, Science and Technics Publishing House, Hanoi (in Vietnamese).

Dang Thanh Hai, Nguyen Duc Vinh, Cao Dinh Trieu, 2002. Long-term earthquake prediction in Lai Chau-Dien Bien region on the basis of time - magnitude model. Journal of Science and Technology, 40(4), 45-53, Hanoi (in Vietnamese).

Dang Thanh Hai, 2003. Study on deep structures of the Earth's crust and seismotectonic zoning in Northern Vietnam. Physics Ph.D. Thesis, 170p, Hanoi (in Vietnamese).

Grishin A.P., 2001. The statistical model for predicting the occurrence time and magnitude of the earthquake". Journal of Volcanology and Seismology (4), 60-65, Russian Academy of Sciences, Moscow. (in Russian).

Grishin A.P., N.V. Kondoskaya, L.E. Levin, L.N. Solodinov, A.L. Petrov, O.M. Petrov, 2001. "Experiment of statistical prediction in Kaspi region (occurrence time, epicenter 


\section{Vietnam Journal of Earth Sciences Vol 38 (3) 231-241}

coordinate and magnitude value of the earthquake). Geophysics in the $21^{\text {th }}$ century, The $3^{\text {rd }}$ Collection of Reading Materials on Geophysics, Scientific World, 149-156

Gubin I.E., 1950. The method of seismotectonic zoning. The projects of The Geophysical Center, Russian Academy of Sciences, 13.

Gumbel E.J., 1958. Statistics of Extremes”. Columbia Univ. Press.

Gutenberg B. and G.F. Richter, 1954. Seismicity of the Earth and associated phenomena. Princeton Univ. Press.

Ngo Thi Lu, Tran Viet Phuong, 2012. About the approach to building algorithms and processes to predict earthquakes by statistical model. Journal of Sciences of the Earth, 34(4), 535-541.

Ngo Thi Lu, Tran Viet Phuong, 2013. Building a new algorithm of the program for separation of forshock and aftershock groups from earthquake catalog to ensure the independence of the events. Journal of Marine Science and Technology. $3 \mathrm{~A}(13), 79-85$

Ngo Thi Lu (Project manager), 2011. Assessment of the seismic potential in Vietnam based on a combination of geological, geophysical and seismic data". The international scientific cooperation between Vietnam Academy of Science and Technology and Russian Academy of Sciences under the state-level protocol (20082010), Final Report, 163p, Hanoi (in Vietnamese).

Ngo Thi Lu (Project manager), 2013. Establishment of experimental program for short-term earthquake prediction based on the statistical model combined with tectonophysics in Vietnam and adjacent regions. The independent project of Vietnam Academy of Science and Technology, Code VAST.DL.09/11-12, 125p, Hanoi (in Vietnamese).

Nguyen Hong Phuong, 1991. Probabilistic assessment of earthquake hazard in Vietnam based on seismotectonic regionalization. Tecronophysics, 198, 81-93.

Nguyen Hong Phuong, 1997. Evaluation of the maximum earthquake for seismic source zones in Vietnam by a combination of probability methods. The scientific works on geology and marine geophysics (3), 48-65, Science and Technics Publishing House, Hanoi (in Vietnamese).

Nguyen Hong Phuong, 2001. Probabilistic Seismic Hazard Assessment Along the Southeastern Coast of Vietnam, Natural Hazards 24, 53-74.

Nguyen Hong Phuong, Pham The Truyen, 2014. Probabilistic Seismic Hazard Assessment for the South Central Vietnam. Vietnam Journal of Earth Sciences 36, 451-461.
Nguyen Dinh Xuyen (Project manager), Nguyen Ngoc Thuy et al., 1996. Database of earthquake mitigation measures in Vietnam. The final report of state-level independent project, Code KT-DL 92-07, 3 volumes, Institute of Geophysics, Hanoi (in Vietnamese).

Nguyen Dinh Xuyen, 2002. Earthquake and earthquake hazard level. Internal document, Institute of Geophysics, Hanoi (in Vietnamese).

Nguyen Dinh Xuyen, Pham Dinh Nguyen, Pham Quang Hung, Nguyen Anh Duong, 2003. Experiment of long-term earthquake prediction based on the mechanism of foreshock activities. Journal of Sciences of the Earth, 25(3), 193-200, Hanoi (in Vietnamese).

Phan Trong Trinh, Ngo Van Liem, Nguyen Van Huong, Hoang Quang Vinh, Bui Van Thom, Bui Thi Thao, Mai Thanh Tan, Nguyen Hoang, 2012. Late Quaternary tectonics and seismotectonics along the Red River fault zone, North Vietnam. Earth-Science Reviews 114(3), 224-235.

Phan Trong Trinh, Hoang Quang Vinh, Nguyen Van Huong, Ngo Van Liem, 2013. Active fault segmentation and seismic hazard in Hoa-Binh reservoir, Vietnam. Cent. Eur. J. Geosci. 5(2), 223-235.

Pham Van Thuc and Kijko, A., 1985. Estimation of maximum magnitude and seismic hazard in Southeast Asia and Vietnam. Acta Geophys. Pol., XXX111 (4), 377-387.

Pham Van Thuc, 2007. Seismology and earthquake in Vietnam. The monographs on natural resources and environment in Vietnam, Publishing House for Science and Technology, Vietnam Academy of Science and Technology, 378p (in Vietnamese).

Reisner G.I., L.I. Ioganson, M.G. Reisner, Iu.E. Baranov, 1993. Characteristic classification of the Earth's crust and the modern geological process. Publishing House of Russian Academy of Sciences, Moscow, 210p (in Russian).

Reisner G.I., L.I. Ioganson, 1996. The Extraregional Seismotectonic Method for the Assessment of Seismic Potential. Natural Hazards 14, 3-10 (Kluwer Academic Publishers, printed in the Netherlands).

Tran Thi My Thanh, 2002. Assessment of seismic hazard in Vietnam and adjacent regions. Physics Ph.D. Thesis, 161 pages, Hanoi (in Vietnamese).

Vu Thi Hoan, Ngo Thi Lu, M.V. Rodkin, Tran Viet Phuong, 2014. Application of the generalized extreme value distribution to study the seismicity of the Southeast Asian. Journal of Geology. Series A, 341-345. Hanoi. 